\title{
Effect of Immediate Postnatal Skin to Skin Contact between Mother Newborn on Time of Placental Delivery and Initiation of Breastfeeding
}

\author{
Reda Mohamed Nabil Aboushay, Lecturer \\ Maternal and Newborn Nursing, Faculty of Nursing, Cairo University \\ Khadiga Abd Elgied Gomaa Hassan, Lecturer \\ Pediatric Nursing, Faculty of Nursing, Port Said University
}

\begin{abstract}
Skin-to-Skin Contact (SSC) has a significant positive effect on exclusive breastfeeding and time of placental delivery. It is a cost-effective method to improve the quality of postnatal care, and is one of the basic steps in achieving Millennium Development Goals 4 and 5 of lowering the mortality of the child and improvement of maternal well-being. Objective: Evaluate the effect of immediate postnatal mothers and newborns skin to skin contact on time of placental delivery and initiation of breast feeding. Setting: This study was conducted at the delivery room in maternity department at Shaqra General Hospital, Shaqra, Kingdom of Saudi Arabia. Subjects: A purposive sample of 100 laboring women was divided into study and control groups (50 for each). Tools: Four tools were used: 1) Laboring Women Structured Interview schedule, 2) Assessment of Labor and Immediate Postnatal, 3) Infant Breastfeeding Assessment (IBFAT) and 4) Neonatal Assessment. Results: There was a significant difference between study and control groups regarding (complete placental separation, uterine contraction immediately after birth, uterus position between umbilical and pubic bone, and uterine atony). The first breastfeed was 58\% more successful in SSC group as compared to routine hospital care group (RHC) $(88 \%$ SSC \& $30 \%$ with a p-value of 0.001). In SSC group, the mean time to initiate first breastfeeding was 70.8 minutes shorter than RHC group $(37.96 \pm 14.80$ vs. $108.82 \pm 31.50$ minutes; $p<0.001)$. Mean time to achieve effective breastfeeding was 275.08 minutes earlier in SSC group (121.92 \pm 39.97 vs. $397 \pm$ 105.54 minutes; $p<0.001)$. Similarly, 82\% mothers of SSC group showed a preference for similar care in future as compared to 32\% in RHC group. Conclusion: SSC was associated with shortage in the time of placental delivery as well as, decrease in time between birth and breastfeeding initiation, more success in the first breastfeeding and longer duration of first breastfeeding. Recommendations: Nurses should encourage mothers to practice skin-to-skin contact immediately after birth. Continuous educational and training program concerning benefits and practice of SSC among health personnel is necessary.
\end{abstract}

Keywords: Skin to Skin Contact (SSC), Initiation of breastfeeding, Time of placental delivery.

\section{Introduction}

In the new millennium, breastfeeding is an important issue in general health for both neonate and his/her mother health national and international policies ${ }^{(1,2)}$. According to, Labbok (2012) more than 1.5 million infants' deaths per year are happening because of insufficient intake of breast milk. The achievement of this goal must focus on understanding the dynamic causes of maternal and neonatal mortality and removing such causes. Postpartum hemorrhage and early neonatal death from inadequate feeding are significant problems $^{(3)}$.

The Baby Friendly Hospital Initiative (BFHI) recommended that babies should be placed in Skin-to-Skin Contact (SSC) with their mothers immediately following birth 
for at least one hour, and mothers helped to initiate breastfeeding within the first halfhour following birth ${ }^{(3)}$. It is one of the Operational Targets of the Global Strategy for Infant and Young Child Feeding endorsed in 2002 by the Fifty-Fifth World Health Assembly and the UNICEF Executive Board $^{(4,5)}$. "Ten Steps to Successful Breastfeeding' were adopted as the minimum standard for hospitals worldwide to gain accreditation as "Baby Friendly". Immediate skin-to-skin contact with the initiation of breastfeeding may decrease newborns morbidity and mortality, and maternal health as well.

Skin to Skin Contact is defined as "placing the naked newborn, prone, on the mother's bare chest instantaneously as soon as possible after birth" ${ }^{\text {(6) }}$. This method, also known as Kangaroo mother care was first introduced in Bogota, Colombia and its effect on breastfeeding behaviors in healthy full-term infants are well documented ${ }^{(7)}$. This contact helps full-term infant move towards the mother's nipples and correctly latch. On the other hand, separation of the infant from the mother in immediate postnatal period causes failure of early initiation and effective breastfeeding. SSC is a well-known caregiving method that facilitates breastfeeding and maintains newborn temperature. The duration of SSC is different between institutions, though $\mathrm{SSC}$ is recommended to last for at least an hour ${ }^{(7,8)}$. The characteristics of SSC also varied between SSC intervention studies. In their review article on early SSC for mothers and their healthy newborn infants, Moore and his colleagues (2007) have divided SSC into 3 subgroups namely Birth SSC, Very early SSC, and Early SSC ${ }^{(9)}$. Breastfeeding not only has positive benefits for baby, but also improves mother wellbeing ${ }^{(10,11)}$. Specifically, it improves maternal recovery following delivery, decreases postpartum blood loss, delays return to fertility, and decreases risk of breast and ovarian cancers. The "BabyFriendly', approach supports immediate postpartum, breastfeeding, helps bonding between mother and child and conveys all the known benefits of breastfeeding, including reduction in cases of abandoned babies $^{(3)}$.

Time of placental delivery starts from birth of the baby to birth of the placenta and is called the third stage of labor. It is an essential time for the health and wellbeing of mother and baby ${ }^{(12,13)}$. It has been noticed in modern obstetric settings, that the use of drugs that cause the uterus to contract strongly to hasten the third stage, in an effort to prevent hemorrhage. Active management is a standardized practice, which includes early clamping of the cord, and pulling on the cord to deliver the baby's placenta quickly. In a spontaneous, uncomplicated birth, it is reasonable to plan a physiological or natural third stage, without increasing the risk of hemorrhage. On natural third stage, the baby's cord usually not clamped or cut and the mother and baby stay on skin- to skin contact, in a warm, unstimulating birthing environment until after the placenta has been birthed. It is important that the midwife or doctor who has the professional responsibility at the time of birth have to be competent in natural third stage, and should not interrupt the natural process without a good reason ${ }^{(14,15)}$.

Immediately after a baby is born, the mother meets her baby for the first time and, if uninterrupted, will experience a natural and instinctive behavioral pattern that supports the establishment of confident mothering, early breastfeeding, and a secure bond or attachment between herself and her baby. This natural process includes a surge in the mother's love hormone, oxytocin, which also causes her uterus to contract, and assists in the birthing of the placenta ${ }^{(15)}$.

\section{Significance of the study}

The first two hours after birth is a critical period for stabilizing breastfeeding and is the time in which the neonates feeding reflexes such as rooting and sucking reflexes strongly exist. During this period, most of the infant's responses to the touch 
mother's as well as thermal and smell instigations received from their mother's body; can start breastfeeding by themselves, so it seems that using neonates innate behaviors for initiating breastfeeding, is a logic step to start interventions aimed to increase the successful breastfeeding ${ }^{(14,15)}$. So, it is necessary to identify proper strategies of promotion and continuation of breastfeeding. In most hospitals, even in baby-friendly hospitals, in which skin-toskin contact is done, this contact is delayed due to performing routine infant care and repairing mother's perineum ${ }^{(16)}$. This problem especially happens in primigravid mothers that their success in breastfeeding requires more support. Therefore, the present study will contribute to a greater understanding of evaluate effect of immediate postnatal mothers and newborns skin to skin contact on time of placental delivery and initiation of breast feeding.

\section{Aim of the Study}

This study aimed to evaluate the effect of immediate postnatal mothers and newborns skin to skin contact on time of placental delivery and initiation of breast feeding.

\section{Research Hypotheses:}

1. Laboring women who practice immediate SSC after delivery exhibit a short duration of placental delivery compared to those who received routine hospital care.

2. Laboring women who practice immediate SSC after delivery exhibit early successful initiation of breastfeeding compared to those who received routine hospital care.

\section{Materials and Method}

Materials

Design: A Quasi-experimental research design was adopted to conduct this research.
Setting: The study was conducted at delivery room in maternity department of Shaqra General Hospital, Shaqra Governorate, Kingdom of Saudi Arabian (KSA).

Subjects: A purposive sample of 100 laboring women were selected and divided equally into two groups namely, skin-toskin contact SSC group $(n=50)$ and routine hospital care group (RHC) $(n=50)$.

Mothers in both groups had to fulfill the following criteria:

- Primigravida and multigravida women.

- Giving birth to pass full-term neonates (38 to 42 weeks of gestation).

- Normal delivery without complications such as dysfunctional labor, dystocia, and signs of fetal distress during labor, general anesthesia during delivery, multiple birth, and cesarean section.

Tools: In order to collect the necessary information for the study the following tools were used:

\section{Tool I: Laboring Women Structured} Interview Schedule

This tool was developed by the researchers after extensive literature review. It included the following sections: 1) First section: included subject's personal data such as (age, educational level, occupational level, and residence). 2) Second section: includes reproductive history as (gestational age, number of pregnancy, number of living children).

\section{Tool II: Labor Assessment}

It was designed by the researcher after extensive literature review to assess the mothers during labor and immediately after labor. It included the following: assessment of uterine contractility immediately after birth, completeness of placenta, presence of uterine atony or excessive blood loss, giving 
methargene, the position of the uterus, and duration of placental delivery.

\section{Tool III: Infant Breastfeeding Assessment Tool (IBFAT)}

It was developed by Mathews $(1998)^{(17)}$. The IBFAT appraises four parameters of infant suckling competence, including readiness to feed, rooting reflex, fixing (Latch on), and suckling pattern. The infant can receive a score for $0-3$ on each item for a maximum total score of 12 . Achieving scores between 10 to 12 showed success and scores less than 10 showed failure in first breast-feeding. IBFAT is a reliable tool for assessing infant success in first breastfeeding which has been used in several studies.

\section{Tool IV: Neonatal Assessment Tool at Birth}

It includes the following section: First section: include Apgar score; it was developed by Apgar(1953) ${ }^{(18)}$. It is a method of rapid evaluation of the infant cardio-respiratory adaptation after birth. The Apgar score consists of five objective signs (heart rate, respiratory rate, muscle tone, reflex irritability and color). These signs are given a score of 0,1 , or 2 evaluated at the first and fifth minutes after delivery and receive the total score ranging from 0 to 10. Second section: include Assessment Tool during Breastfeeding; it was designed by the researcher after extensive literature review. It included the following: time in minutes between delivery and first breastfeeding, duration (minutes) of first breastfeeding, and the assessment of time (in minutes) needed for effective breast feeding in minutes.

\section{Method}

- An official permission was granted from administrative personnel of Shaqra General Hospital to obtain their permission to conduct the study after clarifying the purpose of the study.
- The study tools one and two were developed by the researcher after reviewing the literature relevant to the study and content validity was tested by three experts in maternity nursing field.

- Reliability was assessed by applying the tools twice by two different data collectors on 10 laboring women using test-retest, who were excluded from the study.

- A pilot study was carried out on 10 laboring women to clarify the validity of the questionnaires and to test the research, feasibility, clarity and objectivity of the tools. The sample included in the pilot study was excluded from the study sample, and the necessary modifications were done accordingly

- The selected laboring women were divided into two groups. The first 50 subjects became the control group, and then the next 50 were included in the study group. This was done to avoid sample contamination and bias.

- The average time needed to complete all tools ranged from 1520 min for each mothers.

- Concerning the control group; 50 laboring women who were encouraged to practice routine hospital care after giving birth. Their neonates were shifted to the radiant warmer immediately after cutting the cords as hospital routine care. They were cleaned and wrapped with pre-warm sheets. Infant's APGAR score was determined, it is also routine care. They were transferred to the postnatal ward with mothers and first feed was started when mothers were ready .

- Regarding study group; 50 laboring women who were encouraged to practice immediate postnatal 
maternal and newborn SSC. The naked babies were placed prone against mothers' skin, between the breasts. To prevent heat loss, researcher covered the neonates back with a pre warmed towel and blanket, and the neonatal head was covered with a dry cap immediately after birth till placental delivery and completion of the suturing of spontaneous rupture and/or episiotomies for the mother as hospital policy for both primigravida and multigravida. Infant was closed to the mother's breast to start breastfeeding and Infant Breast Feeding Assessment tool (IBFAT) was completed by one of the researchers to measure the "success in first breastfeeding."

- Infant's APGAR score was determined by the researcher while mother and infant were in skin to skin contact and the baby was suctioned while on the mother's chest, well dried. Ideally, all other interventions were delayed until the end of the first hours post-birth as; weighing, take vitamin $\mathrm{K}$ and general examinations before transferring to the obstetric ward. The neonates were then placed beside their mother soon after routine examination. SSC was ended at any time when the neonates had taken first successful feed and at least 30 minutes had passed.

- The researcher accompanied each mother in both groups from the start of 2nd stage of labor till effective breastfeeding was established. In both groups duration of delivery of placental was measured in minutes and time from birth to start of first feed was noted.

- In both groups, the time from birth to start of first feed was noted. All breastfeeds were scored on IBFAT till the neonates had successful breastfeeding and time for effective breastfeeding was noted.

\section{Ethical considerations:}

A written informed consent was obtained from women who were willing to participate in the research. Before conducting the study confidentiality and anonymity of the women were assured during the coding of the data. Laboring women were assured that the data were not being reused in another research without her acceptance.

\section{Statistical Analysis}

Data were coded and transformed into a specially designed format suitable for computer feeding. All entered data were verified for any errors. Data were analyzed using statistical package for social sciences (SPSS) version 20 windows and were presented in tables. Chi-square analysis was performed. Also mean and standard deviations were computed to evaluate the precipitating factors. An alpha level of 0.05 was used to assess significant differences.

\section{Results}

Table (1) demonstrates that the highest percentage (44\%) of the study group was in age group 30-34 years, while age of $36 \%$ of mothers in the control group ranged between 25-29 years with the mean age of $(29.50 \pm 4.83)(28.54 \pm 4.16)$ respectively. In relation to level of education for mothers (40\% \& 44\%) respectively, for both study and control groups are secondary school graduates. Only $56 \%$ of the subjects were working mothers compared to $72 \%$ housewives in the control group. Highest percentages for both study and control groups (74\% \& $64 \%$ respectively) lived in urban areas. Both groups delivered around 38 weeks of gestation with a mean of $(38.29 \pm 0.72) \&(38.40 \pm 1.19)$ respectively. Most of the study group $(66 \%)$ was primigravida women as compared to $58 \%$ of the control group were multgravida. There 
were no statistical significant differences between the study and control groups in relation to their personal data and obstetric history.

Table (2) shows a significant differences between the study group and the control group in duration time of placental delivery $(\mathrm{p}<0.05)$, complete placenta separation $(\chi 2=6.35, p=.012)$, uterine atony $(\chi 2=13.27$, $\mathrm{p}=.001)$, and giving metheragen $(\chi 2=11.11$, $\mathrm{p}<0.001)$.There were no significant differences in both groups regarding prompt uterine contraction after delivery $(\chi 2=5.36$, $\mathrm{p}=.06)$. The level of the uterus was at or below the level of umbilicus compared to only $86 \%$ and $60 \%$ of the control group.

Table (3) shows the number, percent and mean distribution of assessment neonates at birth. The mean Apgar score in the first minute in control group was $6.10 \pm 1.19$ compared to $7.08 \pm 0.83$ in the study group. There was a significant difference in the Apgar score at one minute $(p<0.05)$ between both groups statistically. The mean Apgar score at five minutes in the control group was $7.30 \pm 0.76$ compared to $8.52 \pm 1.07$ in the study group.

The time between delivery and first breastfeeding was significantly shorter among the study group than in the control group, where the mean time was $37.96 \pm 14.80$ minutes in the study group as compared to $108.82 \pm 31.50$ minutes among the latter $(\mathrm{p}<.01)$. In addition, the duration of first breastfeeding was longer in the study group than in the control group, where the mean duration was $33.06 \pm 10.50$ minutes and $8.62 \pm 1.86$ minutes among the study and control groups, respectively $(\mathrm{p}<.001)$. The time of effective breast feeding was start early in the study group compared to the control group 121.92 \pm 39.97 and $397.00 \pm 105.54$ minutes respectively (table $3)$. There are significant differences in both the groups regarding the successful breastfeeding with the total mean score of IBFAT $11.68 \pm 2.19$ in the study group compared to $9.62 \pm 2.41$ in the control group (table 3). And hence the hypothesis is accepted.

\section{Discussion}

Scientific studied mentioned that, early skin to skin contact between the mother and the neonates gives the mother immediate access to their newborn allows them to feel closer to their babies and helps them initiate successful breast feeding ${ }^{(19)}$. Breastfeeding as the healthiest and most natural way of infant feeding and successful lactation depends mainly on early initiation of breastfeeding $^{(7)}$. Also, it increases the releasing of oxytocin, milk secretion and decrease the incidence of postpartum hemorrhage ${ }^{(20)}$. Early skin to skin contact is a cost-effective process to improve the quality of care, and is one of the basic steps in achieving Millennium Development Goals and of decrease the rate of mortality of the neonates and improvement of maternal wellbeing. This study aimed to evaluate the effect of immediate postnatal mothers and newborns skin to skin contact on time of placental delivery and initiation of breast feeding.

The present study revealed that the average duration of the placental delivery among the study group was 5-10 minutes shorter compared to the control group. This finding is similar to the result of Mejbel \& Ali (2012) and Essa \& Ismail (2015) who had stated that skin to skin is associated with shorter duration of the third stage ${ }^{(15,19)}$. This finding may be related to the skin to skin contact and early breastfeeding helping in releasing oxytocin from the mother's posterior pituitary gland and are significant for milk production, mother-infant bonding and attachment, and strengthening the uterine contractions that will help the placenta to separate, and the uterus to contract down ${ }^{(15,20,21)}$.

The present study results revealed statistical significant differences during the third stage of labor in relation to complete placental separation, immediate uterine 
contraction after birth, uterus position and requiring methargene to cause uterine contraction. This is in the same line with Essa \& Ismail (2015) who reported that there are positive effect of SSC in relation to complete placental separation, immediate uterine contraction after birth, uterus position between umbilicus and pubic bone, absent of any abnormal signs of uterine a tony or postpartum hemorrhage and requiring methargene to cause uterine contraction with statistical significant differences $^{(19)}$. In the same line, study by Mejbel \& Ali (2012) to investigate the effectiveness of Skin-to-Skin contact on the duration of third stage of labor ${ }^{(15)}$. Additionally, the present findings are in accordance with the findings of Joshi randomized control trial ${ }^{(22)}$. She studied the impact of child birth kangaroo care on maternal and neonatal outcomes. She found that Birth Kangaroo Care improves the outcome for the mother in relation to position of uterus, and contractility of uterus as compared to conventional care. Moore \& colleagues (2007) concluded that no adverse effects are found with early SSC on mother health $^{(9)}$.

Early mother-neonates SSC is well known to increase the rate of exclusive breastfeeding. A recent Cochrane systemic review showed significant positive effects skin-to-skin contact on exclusive breastfeeding $^{(7,8)}$. Immediate mother-infant skin-to-skin contact (SSC) after birth has been proven most effective in successful initiation and continuation of breastfeeding ${ }^{(24,25)}$.

Concerning successful initiation of breastfeeding, The result of the present study revealed that, the skin to skin was associated with greater success at the first breastfeeding according to the scores achieved from IBFAT scale, which reflects the preparation of the infant to begin breastfeeding and their performance in sucking the breast, was better in study group than control one. This finding may be related to compression of the fetal head and periodic hypoxia during uterine contractions. These high levels of catecholamines in blood flow cause the olfactory bulbs in the infant's nares to be extremely sensitive to the smells that guide the infant towards the mother's nipple ${ }^{(26,27)}$. As well as, increased tactile and verbal stimulation from the mothers to their newborn babies through skin contact. Immediate mother and newborn skin-to-skin contact (SSC) after birth has been proven most effective in successful initiation and continuation of breastfeeding ${ }^{(25)}$. During SSC between mother and infant, touching and verbal interactions are increased that led to increasing response to stimulus received from mother's body and advancing prefeeding infants' behaviors ${ }^{(2,28)}$. Due to these stimulations, infant begins searching for mother's breast and sucking.

Results of the current study showed that, the average time for initiating the first breastfeeding after childbirth was approximately 37 minutes with successful breast feeding in study group as compared to 108 minutes in the routine hospital care group. Moreover, the first breast feeding duration in the skin to skin group was 33 minutes nearly 3 times more often than the control one (8.6 minutes). According to $\mathrm{WHO}^{(29)}$ emphasized on starting the breastfeeding during the first 30 minutes after birth as the fourth action of babyfriendly hospitals to promote breastfeeding $^{(6)}$. Also in this study, duration of first breastfeeding, in skin to skin contact group was nearly one hour -nearly 3 times more than control group (nearly 17 minutes) which shows the high level of infant's preparation for starting breastfeeding and better skill in sucking the breast in this group that may play a significant role in continuing successful breastfeeding in the future. It was similarly noticed by Bramson et al. (2010) suggested that the length of early skin-to-skin contact positively affects the duration of breastfeeding ${ }^{(30)}$. According to Aghdas \& colleagues $(2014)^{(25)}$ mentioned that time to initiate first feed was also shorter in SSC group which is similar 
to a study by Mahmood et al. (2011) $)^{(7)}$ but in Moore $(2012)^{(10)}$ study this time was equal in both groups.

In another Randomized control trail in England in 2005 Carfoot et al. ${ }^{(31)}$ showed that the success of the first breastfeeding rate was not statistically different between the SSC group and controls. This could be due to a difference in scoring of success between this study and the Carfoot study. This findings in consistent with Moore \& Anderson $(2007)^{(9)}$ evaluated the effect of very early SSC on breastfeeding status and did not prove any significant advantage on breastfeeding exclusivity at 1 month postpartum. They used the IBFAT scores from 8 to 12 as a successful first breastfeeding experience. While in the present study, the achievement of success was measured with scores ranging from 10 to 12 . Any score lower than 10 were considered unsuccessful. This may be related to separating infant and mother early after birth will have an important role in making disturbance in breastfeeding initiation. Another study done by Srivastava and colleagues $(2014)^{(32)}$ concluded that mother and baby should not be separated after birth, rather kept in close SSC with each other so that there is no hindrance to the silent conversation ongoing between the two of them.

\section{Conclusion}

This study has shown that there were significant differences between study and control groups in relation to incomplete placental delivery, uterus contraction immediately after birth, uterus position between umbilicus and pubic bone, absence of any abnormal signs of uterine atony or postpartum hemorrhage.

The mean time of initiation of first breastfeeding was shorter in the study group as compared to the control group with statistical significant differences.
Skin to skin contact is an easy, inexpensive and non-invasive method of enhancement of breastfeeding.

\section{Recommendations}

Based on the findings of the current study the following is recommended:

1. Nurses should encourage mothers to practice skin-to-skin contact immediately after birth.

2. Maternity hospitals should include SSC in their policies.

3. Early separation of mother and newborn should be strongly discouraged.

4. Continuous educational and training program concerning benefits and practice of SSC have to be conducted to health personnel periodically.

5. Mass media should have a role in raising the awareness of mothers regarding importance, benefits and practice of SSC.

6. This area of research needs additional efforts in order to expand the evidence base on the association between SSC and exclusive breastfeeding as well as, placental expulsion.

\section{Acknowledgment}

Our appreciation and gratitude to laboring women who agreed to participate in the study and gave us the opportunity to accomplish the study. 
Table (1): Percentage distribution of personal data and reproductive history among laboring women

\begin{tabular}{|c|c|c|c|c|}
\hline \multirow{2}{*}{$\begin{array}{l}\text { Personal data and } \\
\text { reproductive history }\end{array}$} & \multicolumn{2}{|c|}{ Control group } & \multicolumn{2}{|c|}{ Study group } \\
\hline & $\mathbf{n}$ & $\%$ & $\mathbf{n}$ & $\%$ \\
\hline \multirow[t]{2}{*}{ 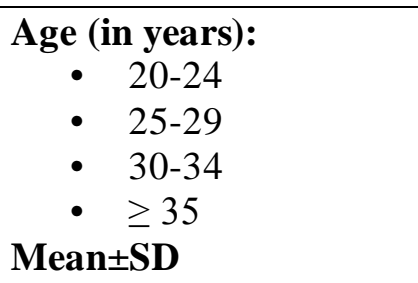 } & $\begin{array}{c}7 \\
18 \\
16 \\
9\end{array}$ & $\begin{array}{l}14 \\
36 \\
32 \\
18\end{array}$ & $\begin{array}{c}7 \\
15 \\
22 \\
6\end{array}$ & $\begin{array}{l}14 \\
30 \\
44 \\
12\end{array}$ \\
\hline & \multicolumn{2}{|c|}{$29.50 \pm 4.83$} & \multicolumn{2}{|c|}{$28.54 \pm 4.16$} \\
\hline $\begin{array}{ll}\text { Education } \\
\text { - } \\
\text { - } \text { Pead \& wrimary education } \\
\text { - } \text { preparatory } \\
\text { - } \text { secondary } \\
\text { - } \text { university } \\
\end{array}$ & $\begin{array}{c}1 \\
9 \\
11 \\
22 \\
7\end{array}$ & $\begin{array}{c}2 \\
18 \\
22 \\
44 \\
14\end{array}$ & $\begin{array}{c}6 \\
10 \\
10 \\
20 \\
7 \\
\end{array}$ & $\begin{array}{l}12 \\
20 \\
20 \\
40 \\
14\end{array}$ \\
\hline $\begin{array}{l}\text { Occupation } \\
\qquad \text { Working } \\
\text { - House wives }\end{array}$ & $\begin{array}{l}14 \\
36\end{array}$ & $\begin{array}{l}28 \\
72\end{array}$ & $\begin{array}{l}28 \\
22\end{array}$ & $\begin{array}{l}56 \\
44\end{array}$ \\
\hline $\begin{array}{r}\text { Residence } \\
\text { - Rural } \\
\text { - Urban }\end{array}$ & $\begin{array}{l}18 \\
32\end{array}$ & $\begin{array}{l}36 \\
64\end{array}$ & $\begin{array}{l}13 \\
37\end{array}$ & $\begin{array}{l}26 \\
74\end{array}$ \\
\hline $\begin{array}{l}\text { Gestational age } \\
\text { • weeks }(\mathrm{M} \pm \mathrm{SD})\end{array}$ & \multicolumn{2}{|c|}{$38.29 \pm 0.72$} & \multicolumn{2}{|c|}{$38.40 \pm 1.19$} \\
\hline $\begin{aligned} \text { Parity } & \\
\bullet & \text { Primigravida } \\
\bullet & \text { Multigravida }\end{aligned}$ & $\begin{array}{l}21 \\
29\end{array}$ & $\begin{array}{l}42 \\
58\end{array}$ & $\begin{array}{l}33 \\
17\end{array}$ & $\begin{array}{l}66 \\
34\end{array}$ \\
\hline
\end{tabular}

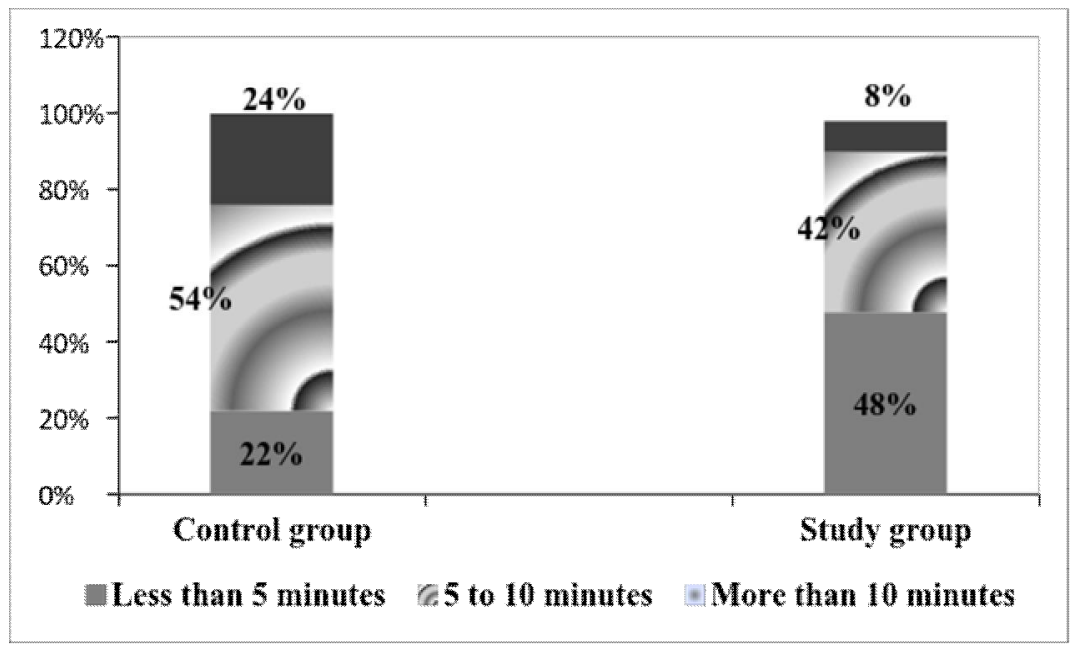

Figure (1): Duration of the placenta delivery among both groups 
Table (2): Distribution of maternal assessment during labor for the studied sample

\begin{tabular}{|c|c|c|c|c|c|}
\hline \multirow[t]{2}{*}{ Maternal assessment } & \multicolumn{2}{|c|}{$\begin{array}{c}\text { Control group } \\
(n=50)\end{array}$} & \multicolumn{2}{|c|}{$\begin{array}{c}\text { Study group } \\
(\mathbf{n}=50)\end{array}$} & \multirow[t]{2}{*}{ p-value } \\
\hline & $\mathbf{n}$ & $\%$ & $\mathbf{n}$ & $\%$ & \\
\hline $\begin{array}{l}\text { Type of delivery } \\
\qquad \text { NVD } \\
\text { - } \text { VD with episiotomy }\end{array}$ & $\begin{array}{l}23 \\
27\end{array}$ & $\begin{array}{l}46 \\
54\end{array}$ & $\begin{array}{l}22 \\
28\end{array}$ & $\begin{array}{l}44 \\
56\end{array}$ & $\mathrm{p}>0.05$ \\
\hline $\begin{array}{l}\text { Duration of the placental delivery } \\
\text { - } \quad<5 \text { minutes. } \\
\text { - } 5-10 \text { minutes. } \\
\text { - }>10 \text { minutes }\end{array}$ & $\begin{array}{l}11 \\
27 \\
12\end{array}$ & $\begin{array}{l}22 \\
54 \\
24\end{array}$ & $\begin{array}{l}24 \\
21 \\
4\end{array}$ & $\begin{array}{c}48 \\
42 \\
8\end{array}$ & $\mathrm{p}>0.05$ \\
\hline $\begin{array}{l}\text { Complete delivery of placental } \\
\begin{array}{l}\text { - Yes } \\
\text { - No }\end{array}\end{array}$ & $\begin{array}{l}38 \\
12\end{array}$ & $\begin{array}{l}76 \\
24\end{array}$ & $\begin{array}{c}47 \\
3\end{array}$ & $\begin{array}{c}94 \\
6\end{array}$ & $\mathrm{p}>0.05$ \\
\hline $\begin{array}{l}\text { Uterus contracted immediately } \\
\text { - Yes } \\
\text { - No }\end{array}$ & $\begin{array}{l}34 \\
16\end{array}$ & $\begin{array}{l}68 \\
32\end{array}$ & $\begin{array}{c}50 \\
0\end{array}$ & $\begin{array}{l}100 \\
0.0\end{array}$ & $\mathrm{p}>0.05$ \\
\hline $\begin{array}{l}\text { Position of the uterus } \\
\text { - At the level of umbilicus } \\
\text { below } \\
\text { - Above the level of umbilicus }\end{array}$ & $\begin{array}{l}30 \\
20\end{array}$ & $\begin{array}{l}60 \\
40\end{array}$ & 7 & $\begin{array}{l}86 \\
14\end{array}$ & $\mathrm{p}>0.05$ \\
\hline $\begin{array}{c}\text { Giving Metheragen } \\
\text { - Yes } \\
\text { - No }\end{array}$ & $\begin{array}{l}40 \\
10\end{array}$ & $\begin{array}{l}80 \\
20\end{array}$ & $\begin{array}{l}24 \\
26\end{array}$ & $\begin{array}{l}48 \\
52\end{array}$ & $p>0.05$ \\
\hline $\begin{array}{l}\text { Uterine Atony } \\
\text { - } \text { Yes } \\
\text { - No }\end{array}$ & $\begin{array}{l}16 \\
34\end{array}$ & $\begin{array}{l}32 \\
68\end{array}$ & $\begin{array}{c}2 \\
48\end{array}$ & $\begin{array}{c}4 \\
96\end{array}$ & $p>0.05$ \\
\hline
\end{tabular}


Table (3): Percentage distribution of neonatal assessment at birth among both groups

\begin{tabular}{|c|c|c|c|c|c|}
\hline \multirow[t]{2}{*}{ Neonatal assessment } & \multicolumn{2}{|c|}{$\begin{array}{c}\text { Control group } \\
(n=50)\end{array}$} & \multicolumn{2}{|c|}{$\begin{array}{l}\text { Study group } \\
\quad(n=50)\end{array}$} & \multirow[t]{2}{*}{ p-value } \\
\hline & $\mathbf{n}$ & $\%$ & $\mathbf{n}$ & $\%$ & \\
\hline $\begin{aligned} \text { Apgar } & \text { score } \\
\text { - } & \text { First minutes } \\
\text { - } & \text { Fifth minutes }\end{aligned}$ & \multicolumn{2}{|c|}{$\begin{array}{l}6.10 \pm 1.19 \\
7.30 \pm 0.76\end{array}$} & \multicolumn{2}{|c|}{$\begin{array}{l}7.08 \pm 0.83 \\
8.52 \pm 1.07\end{array}$} & $\mathrm{p}>0.05$ \\
\hline $\begin{array}{c}\text { Sex of the baby } \\
\text { - } \quad \text { Male } \\
\text { - } \quad \text { Female }\end{array}$ & $\begin{array}{l}29 \\
21\end{array}$ & $\begin{array}{l}58 \\
42\end{array}$ & $\begin{array}{l}23 \\
27\end{array}$ & $\begin{array}{l}46 \\
54\end{array}$ & $\mathrm{p}<0.05$ \\
\hline Total score of IBT & \multicolumn{2}{|c|}{$9.62 \pm 2.41$} & \multicolumn{2}{|c|}{$11.68 \pm 2.19$} & $\mathrm{p}>0.05$ \\
\hline $\begin{array}{l}\text { Successful breastfeeding } \\
\text { Unsuccessful breastfeeding }\end{array}$ & $\begin{array}{l}15 \\
35\end{array}$ & $\begin{array}{l}30 \\
70\end{array}$ & $\begin{array}{c}44 \\
6\end{array}$ & $\begin{array}{l}88 \\
12\end{array}$ & $\mathrm{p}>0.05$ \\
\hline $\begin{array}{l}\text { Time of initiate first } \\
\text { breastfeeding (minutes) }\end{array}$ & \multicolumn{2}{|c|}{$108.82 \pm 31.50$} & \multicolumn{2}{|c|}{$37.96 \pm 14.80$} & $\mathrm{p}>0.05$ \\
\hline $\begin{array}{l}\text { Duration of first breastfeeding } \\
\text { (minute) }\end{array}$ & \multicolumn{2}{|c|}{$8.62 \pm 1.86$} & \multicolumn{2}{|c|}{$33.06 \pm 10.50$} & $\mathrm{p}>0.05$ \\
\hline $\begin{array}{l}\text { Time of effective breastfeeding } \\
\text { (minutes) }\end{array}$ & \multicolumn{2}{|c|}{$397.00 \pm 105.54$} & \multicolumn{2}{|c|}{$121.92 \pm 39.97$} & $\mathrm{p}>0.05$ \\
\hline
\end{tabular}




\section{References}

1. Khadivzadeh T, Karimi, A. The effects of post-birth mother-infant skin to skin contact on first breastfeeding. Iranian Journal of Nursing and Midwifery Research 2009; 14(3).

2. Gabriel M, Llana Martín, I, López Escobar A, Fernández Villalba E, Romero Blanco I, Touza Pol P. Randomized controlled trial of early skin - to - skin contact: effects on the mother and the newborn. Acta Paediatrica 2010; 99(11): 1630-1634.

3. Labbok MH. Global baby-friendly hospital initiative monitoring data: update and discussion. Breastfeeding Medicine 2012; 7(4): 210-222.

4. Saadeh R, Casanovas C. Implementing and revitalizing the Baby-Friendly Hospital Initiative. Food \& Nutrition Bulletin 2009; 30(Supplement 2): 225S229S.

5. D'Artibale, EF, Bercini LO. The practice of the fourth step of the baby friendly hospital initiative. Escola Anna Nery 2014; 18(2): 356-364.

6. Sauder E. Skin-to-Skin Contact after Birth Benefits Moms, Newborns. Healthy Newborn Network. 2012. Retrieved on: 30 March 2014, from http://www.healthynewbornnetwork.org /press-release/skin-skin-contact-afterbirth-benefitsmoms-newborns.

7. Mahmood I, Jamal M, Khan N. Effect of mother-infant early skin-to-skin contact on breastfeeding status: a randomized controlled trial. J Coll Physicians Surg Pak 2011; 21(10): 601605.

8. Cantrill RM, Creedy DK, Cooke M, Dykes F. Effective suckling in relation to naked maternal-infant body contact in the first hour of life: an observation study. BMC pregnancy and childbirth 2014; 14(1): 20.

9. Moore ER, Anderson GC. Randomized controlled trial of very early motherinfant skin-to-skin contact and breastfeeding status. J Midwifery Women Health 2007; 52(2): 116-25.

10. Moore ER, Anderson, GC, Bergman N, Dowswell T. Early skin-to-skin contact for mothers and their healthy newborn infants. Cochrane Database Syst Rev 2012; 5.

11. Semenic S, Childerhose JE, Lauzière J, Groleau D. Barriers, facilitators, and recommendations related to implementing the Baby-Friendly Initiative (BFI): an integrative review. Journal of Human Lactation 2012; 0890334412445195.

12. Begley CM, Gyte GM, Devane D, McGuire W, Weeks A. Active versus expectant management for women in the third stage of labour. Cochrane Database Syst Rev 2011; 11:11.

13. Begley CM, Gyte GM, Devane D, McGuire W, Weeks A. Active versus expectant management for women in the third stage of labour. The Cochrane Library. 2015.

14. Buckley SJ. Gentle Birth, Gentle Mothering: the wisdom and science of gentle birth choices in pregnancy, $\mathbf{J}$ birth and parenting 2005; 202.

15. Mejbel M, Ali R. Effectiveness of Skinto Skin Contact on duration of third stage of labor in Baghdad Teaching Hospital: Comparative Study. Kufa Journal for Nursing Sciences 2012; 2(3): 1-13.

16. Svensson KE, Velandia MI, Matthiesen AS, Welles-Nyström BL, Widström AME. Effects of mother-infant skin-toskin contact on severe latch-on problems in older infants: a randomized 
trial. International breastfeeding journal 2013; 8(1): 1-13.

17. Mathews MK. Developing an instrument to assess infant breastfeeding behavior in the early neonatal period. Midwifery 1998; 4:154-65. 1016/S0266-6138(88)80071-8 from http://dx.doi.org/10.1HYPERLINK http://dx.doi.org/10.1016/S0266$\underline{6138(88) 80071-8 " 016 / \mathrm{S} 0266-}$ $\underline{6138(88) 80071-8}$.

18. Apgar V. A proposal for a new method of evaluation of the newborn. Curr Res Anaesth 1953; 32: 260-267.

19. Essa RM, Ismail NI. A. A. Effect of early maternal/newborn skin-to-skin contact after birth on the duration of third stage of labor and initiation of breastfeeding. Journal of Nursing Education and Practice 2015; 5(4): 98.

20. Hahn-Holbrook, Jennifer, Julianne HoltLunstad, Colin Holbrook, Sarah M. Coyne, and E. Thomas Lawson. "Maternal Defense Breast Feeding Increases Aggression by Reducing Stress". Psychological science 2011.

21. Fahy K, Hastie C, Bisits A, Marsh C, Smith L, Saxton A. Holistic physiological care compared with active management of the third stage of labour for women at low risk of postpartum haemorrhage: A cohort study. Women and Birth 2010; 23(4): 146-152.

22. Joshi S. The effect of birth kangaroo care on maternal and neonatal outcome: A randomized, controlled trial. Sinhgad e Journal of Nursing 2012; 2(2): 13-17.

23. Beiranvand $\mathrm{S}, \quad$ Valizadeh $\mathrm{F}$, Hosseinabadi R. The effect of skin-toskin contact of mother and newborns on breastfeeding status in full-term newborns after cesarean delivery. Modern Care Journal 2014; 10(4): 288-295.
24. Widström AM, Lilja G, Aaltomaa - Michalias P, Dahllöf A, Lintula M, Nissen E. Newborn behavior to locate the breast when skin to skin: a possible method for enabling early selfregulation. Acta paediatrica 2011; 100(1): 79-85.

25. Aghdas K, Talat K, Sepideh B. Effect of immediate and continuous motherinfant skin-to-skin contact on breastfeeding self-efficacy of primiparous women: A randomised control trial. Women and Birth 2014; 27(1): 37-40.

26. Takahashi Y, Tamakoshi K, Matsushima M, Kawabe T. Comparison of salivary cortisol, heart rate, and oxygen saturation between early skinto-skin contact with different initiation and duration times in healthy, full-term infants. Early human development 2011; 87(3): 151-157.

27. Thukral A, Sankar MJ, Agarwal R, Gupta N, Deorari AK, Paul VK. Early skin-to-skin contact and breast-feeding behavior in term neonates: A randomized controlled trial. Neonatology 2012; 102(2): 114-119.

28. Redshaw M, Hennegan J, Kruske S. Holding the baby: Early mother-infant contact after childbirth and outcomes. Midwifery 2014;30(5): e177-e187.

29. WHO. Participant's manual, part three, Sessions 1-9. 2010. [Retrieved on: 26 Mar 2007], from: http://www.who.int/child_adolescent_h ealth/documents/pdfs/bc_participants_m anual.pdf.

30. Bramson L, Lee JW, Moore E, Montgomery S, Neish C, Bahjri K, Melcher CL. Effect of early skin-to-skin mother-infant contact during the first 3 hours following birth on exclusive breastfeeding during the maternity 
hospital stay. Journal of Human Lactation. 2010.

31. Carfoot S, Williamson P, Dickson RA. randomised controlled trial in the north of England examining the effects of skin-to-skin care on breast feeding. Midwifery 2005; 21(1): 71-9.
32. Srivastava S, Gupta A, Bhatnagar A, Dutta S. Effect of very early skin to skin contact on success at breastfeeding and preventing early hypothermia in neonates. Indian journal of public health 2014; 58(1): 22. 